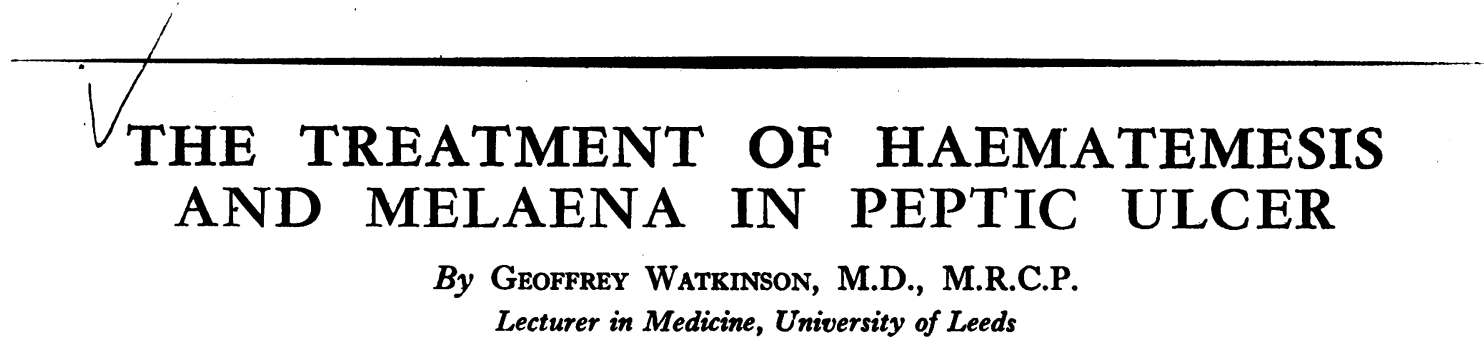

Haematemesis and melaena are amongst the more acute and serious complications of peptic ulcer and their medical management has altered appreciably in the last decade. The re-introduction of liberal feeding by Meulengracht (1953), the use of adequate blood transfusions (Marriot and Kekwick, r935) and the increasing role of surgery in selected cases may be cited. The effects of recent therapeutic advances on the mortality of the bleeding ulcer have been favourably reviewed from the physician's angle by Avery Jones (1947, 1950) and from that of the surgeon by Tanner (1950). Both complications still have a high mortality, particularly in the older age groups, and there is certainly no room for complacency about the results already achieved.

\section{Principles of Treatment}

On immediate examination it may be difficult to assess the degree of resuscitation necessary to combat the shock and to decide whether the patient is bleeding from a chronic or an acute ulcer, as the management of the case will vary according to the type of ulcer.

The aim of immediate treatment should be the correction of dehydration and the maintenance of a near to normal haemoglobin level in order to minimise cellular anoxaemia. An adequate fluid, calorie and vitamin intake should be provided from the outset in order to render the patient most able to withstand a further haemorrhage and to undergo surgical treatment if required. Medical treatment should be continued until healing of the lesion has occurred or until surgical excision has been completed.

\section{Assessment of the Patient}

The initial assessment of the patient will depend on obtaining a careful history, the clinical examination of the use of certain pathological data. There would seem to be an increasing case for the use of gastroscopy, gastric aspiration and earlier barium 3 meal examination.

\section{History}

A history of faintness or collapse at the time of bleeding usually indicates a significant degree of blood loss. The character of the vomitus must be described, fresh blood indicating brisk haemorrhage.

A history of an ulcer type of dyspepsia exceeding a few weeks in duration is more suggestive of a chronic than an acute ulcer. Pain is usualig of relieved by bleeding and its persistence of exacerbation suggests that an associated complica tion such as a perforation is present.

Disorientation due to cerebral anoxaemia may render an accurate diagnosis difficult whilst associated cardiac failure, angina or coronary $\&$ infarction may mask the initial causal conditions.

\section{Clinical Examination}

The clinical examination is first directed to an assessment of the degree of shock, note being taken of the patient's pallor, the degree of hydration as assessed by skin elasticity and dryness of the tongue. An hourly record of the pulse rate and blood pressure should be maintained. Abdominal examination, carefully performed, may yield information as to the cause of the bleeding. Thus abdominal masses may be palpated, splenomegaly may indicate portal hypertension, whilst tenderness and guarding may reveal an associated perforation.

\section{Pathological Data}

An estimation of the haemoglobin level should be made on admission, but may be misleadingly high because in the early stages haemodilution has not occurred. An elevated blood urea is not uncommon in the few days following the haemorrhage but figures in excess of $150 \mathrm{mg}$. per cent. 
indicate severe dehydration and alkalosis and the possibility of associated chronic renal disease must be borne in mind.

\section{Emergency Barium Meal and Gastroscopy}

The increasing place of surgery in the treatment of haematemesis has demanded that all possible information be accumulated for the surgeon from the onset of bleeding. Whilst the barium meal examination is usually postponed until the patient can stand, i.e., after two to three weeks, in certain acute cases where surgery is contemplated an early barium meal after transfusion may yield useful information and has been widely used in the Scandinavian countries. The examination can only be of positive value if a definite lesion is demonstrated, a negative $\mathrm{X}$-ray at this stage does not exclude disease. The clinician should accompany the patient to the X-ray department as the radiologist cannot be expected to assume clinical responsibility for the welfare of the patient during the examination. Gastroscopy can be performed at any time, sometimes the field is obscured by blood, but occasionally useful positive information is obtained.

\section{Gastric Aspiration}

In the belief that the introduction of foreign bodies into the stomach might cause or prolong bleeding clinicians have been reluctant to use an indwelling tube in the management of haematemesis cases. Kinsella (1947), advocated the use of immediate gastric aspiration in cases of gastroduodenal bleeding, regarding the procedure as both safe and informative. More recently Chandler and Watkinson (1953) have successfully applied this method to I05 patients with haematemesis or melaena.

Intermittent aspiration of small samples of gastric contents is performed from the time of admission, at hourly intervals. The presence of fresh or old blood is recorded for every specimen on a specially designed chart for this purpose, together with measurements of the pulse rate, the blood pressure, all episodes of haemorrhage and the amounts of transfused blood. This record of progress has proved of great value in the hour to hour management of the patient. No evidence was obtained that the presence of an indwelling tube stimulated recurrence of bleeding or favoured its continuance, nor was the mortality rate adversely affected. The overall mortality in ro5 patients so investigated was 2.9 per cent. and compared very favourably with other reported series:

The presence of fresh blood in the aspirated specimens was of diagnostic value in that warning of continued or recurrent bleeding was obtained before other criteria indicated the occurrence. Occasionally information as to the ulcer site was obtained. Usually fresh blood disappeared from the specimens a few hours after the haemorrhage had occurred. The imminence of further haemorrhage was anticipated, often by many hours, by the reappearance of fresh blood in the aspirated specimens before other criteria had indicated relapse.

A patient known to be bleeding from a chronic gastric ulcer vomited blood twice on the first day and appeared to improve after transfusion. Although the pulse rate and blood pressure remained steady, fresh blood was consistently withdrawn from the stomach antedating by many hours a third haematemesis on the fifth day. Similar evidence of recurrent bleeding was obtained in 26 patients and proved of great value in those patients with acute or chronic gastric ulcers.

Evidence as to the site of the ulcer was obtained in seven patients admitted with haematemesis. In these patients although the continuance of bleeding was indicated by the tachycardia, shock, "and passage of melaena stools, the gastric samples remained free from blood suggesting that the source of bleeding lay distal to the stomach. All, as anticipated, had duodenal ulcers. The simple bedside observation of blood staining in samples of gastric contents can provide much useful information and I agree with Kinsella (1947) in advocating its routine use.

By studying the hourly changes in intragastric $\mathrm{pH}$ for the 24 hours after admission (James and Pickering 1949, Watkinson 1951, Watkinson and James I95 I) valuable diagnostic information was obtained in 73 of 85 patients in whom the secretion patterns were regarded as abnormal. (Chandler and Watkinson 1953.). The finding of a high night acidity facilitated the accurate diagnosis in 27 of 35 patients bleeding from chronic duodenal ulcers. Low nocturnal acidity values, with free acid during the day occurred in 14 of 17 patients with chronic gastric ulcer, again providing diagnostic information in a significant proportion. More important was the finding of achlorhydria, $\mathrm{pH}$ values more alkaline than $\mathrm{pH} 3.5$ throughout the initial 24 hours. This finding occurred in 32 of 36 patients ultimately classed as acute ulcers. The achlorhydria was found to be a temporary condition, the patient's normal acid pattern usually returned after several days. The finding of achlorhydria in the acute stages of gastroduodenal haemorrhage is thought to be an added indication for continued medical treatment. In conclusion it is suggested that early gastric aspiration is a safe and informative method and may yield appreciable 
help in the management of patients after haematemesis.

\section{Management}

The patient is put to bed and is reassured as excessive anxiety may well aggravate the bleeding. For this purpose sedatives may be required, 3 gr. of soluble phenobarbitone by intramuscular injection is frequently sufficient, morphia $\frac{1}{6}$ to $\frac{1}{4} \mathrm{gr}$. being reserved for cases in whom excessive shock or restlessness is present. The foot of the bed may be raised if marked circulatory collapse is present. A specimen of oxalated venous blood is examined for haemoglobin, blood urea and blood group estimation, Rhesus type grouping being particularly important in women.

\section{Blood Transfusion}

The first question to be decided is whether transfusion is necessary and no hard and fast rules can be laid down, each patient presenting an individual problem. If there has been a severe haemorrhage with marked collapse, a persistent tachycardia, a low blood pressure and a haemogoblin of less than $5^{\circ}$ per cent. continued bleeding is obviously occurring and immediate transfusion is necessary. Similarly if serial observations reveal a rising pulse rate, or a falling blood pressure transfusion must obviously be commenced. A blood urea in excess of $150 \mathrm{mg}$. is an indication for extra fluids though not necessarily blood. The continued withdrawal of fresh blood or its reappearance on gastric aspiration is further evidence of continued or recurrent haemorrhage and the need for transfusion.

The transfusion must be carefully performed, the rate and amount of blood given depending on the initial condition and progress of the patient. In 'general a rate of 40 drops per minute and two bottles of blood are desirable initially a watch being kept on the jugular neck veins while the transfusion is being given as acute heart failure may occur in anaemic patients.

There can be no doubt that transfusion has improved the overall mortality in these patients and there is no evidence that raising the blood pressure stimulates further haemorrhage.

\section{Diet}

Although the liberal diet advised by Meulengracht has not been fully accepted in this country, early liberal feeding is now widely used. The patient should be given two hourly $5 \mathrm{oz}$. milk feeds initially and later a purée diet providing adequate calorific intake free from irritant particles. A suitable diet is described by Avery Jones (1953).

\section{Puree Diet}

6 a.m. . Cup of milky tea.

8 a.m. Porridge and Bemax; thin bread-andbutter and jelly marmalade; cup of $\frac{c}{c}$ milky tea.

ro a.m. Cup of milk and biscuit.

I2 noon Minced meat, chicken, or steamed fish; mashed potato; carrot purée or $\frac{\bar{D}}{\bar{D}}$ cauliflower.

2 p.m. Egg custard or cereal pudding or apple $\stackrel{\overparen{D}}{\propto}$ purée; orange juice.

4 p.m. Cup of milky tea; three slices of thin bread-and-butter; bramble jelly; sponge cake.

6 p.m. Vegetable soup or minced chicken sandwich.

8 p.m. Milk pudding or cup of milk.

ro p.m. Cup of milk and biscuit.

Milk feeds during the night if awake: Fluids to be tepid and not hot.

\section{Other Treatments}

It is sometimes desirable to give an antacid $\vec{c}$ after admission in cases with persistent pain and aludrox $\frac{1}{2}$ oz. two hourly is most suitable. Additional ascorbic acid should be given, $200 \mathrm{mg}$. three times daily and in nervous patients prolonged $\overrightarrow{0}$ sedation is beneficial with phenobarbitone $\frac{1}{2}$ to $\frac{\Phi}{\Phi}$ or gr. three times daily. Iron therapy orally of intravenously will hasten the rate of bloo regeneration. Constipation frequently follows haematemesis and no enemas or aperients should be given until five days after haemorrhage has $\frac{\circ}{\mathbb{D}}$ ceased. A milk drip may be desirable in patients with duodenal ulcer where pain persists after $\stackrel{ }{3}$ bleeding and can easily be combined with the gastric aspiration technique already described. Any evidence of anoxaemia, particularly of the elderly, is a definite indication for oxygen therapy.

\section{Indications for Surgery}

The place of early surgery in haematemesis is assuming greater importance and the low mortality rates obtained by Tanner (1950) provide a 의 challenge to accepted medical methods. If $>$ surgery is to be undertaken it should be undertaken early, so that the surgeon is presented with a fair $\bar{N}$ operative risk and there is scope for organized team work between physicians, surgeons and $\tilde{O}$ pathologists. The place of surgery is discussed $\mathbb{\omega}^{\circ}$ elsewhere and will only be summarised here. Operation should be advised in a patient aged over $\varrho$ 45 years, with good clinical evidence of a chronic peptic ulcer, or in whom recurrent bleeding occurs after the institution of medical treatment. It is in this group that associated hypertension and arteriosclerosis adversely affect the mortality but 
also where many chronic medical diseases such as chronic bronchitis, coronary disease, obesity and chronic renal disease furnish many poor operative risks.

An absolute indication for surgery exists when the associated complications of perforation and pyloric stenosis occur, always after suitable correction of body fluid and electrolyte balance.

Younger patients whose assessment suggests a diagnosis of acute ulcer remain the debatable group; operation is indicated in patients with recurrent haemorrhage in the older age groups, but should not be so readily considered for younger patients. Even in the latter, however, recurrent bleeding may make operation necessary. The best surgical method of dealing with the acute ulcer has not been determined. Some surgeons favour gastrectomy, some local excision (Bohn) and some feel that no operation should be undertaken. There is no doubt that a gastrectomy for pain produces better results than a gastrectomy for bleeding (Avery Jones 195I).

\section{Prognosis}

The reader is referred to the excellent series of 6I 5 patients reported by Avery Jones (1947) for information as to the likely outcome of this condition. The mortality rate was shown first to be affected by the site and type of ulcer, being highest in chronic gastric ulcer (I9 per cent.) and lowest in the acute ulcer group ( 2 per cent.). Age is perhaps the most important adverse factor in the prognosis of the condition whereas the mortality below 40 years is less than 2 per cent., the rate steadily increases in successive decades reaching 12.5 per cent. between 60 and 69 and 21.3 per cent. over 70 years. Neither the length of the history, nor the age and sex of the patient have any bearing on the mortality but naturally associated chronic medical diseases gravely influence the prognosis.

\section{Conclusions}

Only by well organized team work between physicians, surgeons and pathologists can the mortality of this grave complication of peptic ulceration be improved. The institution of liberal feeding, blood transfusion and the increasing use of surgical treatment has done much to achieve this end but there is still room for improved treatment particularly in the older age groups. Every effort should be made to establish an accurate diagnosis early and to this end the wider application of early barium meal examination, gastroscopy and immediate aspiration is advocated.

My thanks are due to Professor R. E. Tunbridge for his kind help in the preparation of this paper.

\section{BIBLIOGRAPHY}

AVERY JONES, F. (1947), Brit. med. F., 2, 44 I.

AVERY JONES, F. (I952), ' Modern Trends in Gastroenterology,' Butterworth \& Co. Ltd., London, 432.

AVERY JONES, F. (1952), 'Medical Treatment': Edited by G. Evans, Butterworth \& Co. Ltd., London.

BOHN, G. (1949), Brit. med. F., 2, 630 .

CHANDLER, G. N., and WATKINSON, G. (1953), Lancet.قै In press.

JAMES, A. M. and PICKERING, G. W. (1949), Clin. Sci., 8, I8I MEULENGRACHT, E. (1935), Lancet, ii, 1220.

MARRIOT, H. L. and KEKWICK, A. (I935), Lancet, i, 977.

WATKINSON, G. (195I), Gastroenterology, 18, 377.

WATKINSON, G. and JAMES, A. M. (1951), Clin. Sci., xo, 255.

\section{RUTHIN CASTLE, NORTH WALES}

A Clinic for the diagnosis and treatment of Internal Diseases (except Mental or Infectious Diseases). The Clinic is provided with a staff of doctors, technicians and nurses.

The surroundings are beautiful. The climate is mild. There is central heating throughout. The annual rainfall is 30.5 inches, that is, less than the average for England.

The Fees are inclusive and vary according to the room occupied.

For particulars apply to THE SECRETARY, Ruthin Castle, North Wales. 